\title{
Proficiency in the multiplicative conceptual field: using Rasch measurement to identify levels of competence
}

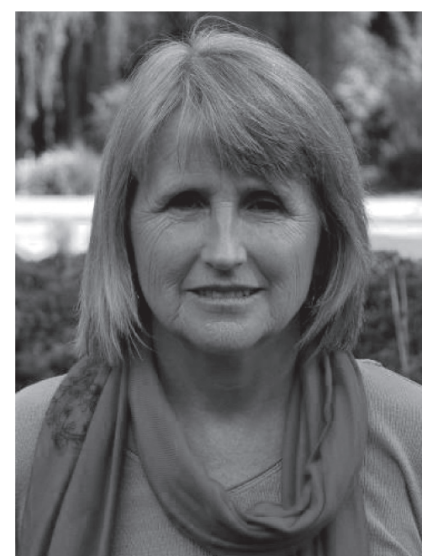

Caroline Long

Centre for Evaluation and Assessment, University of Pretoria Caroline.long@up.ac.za

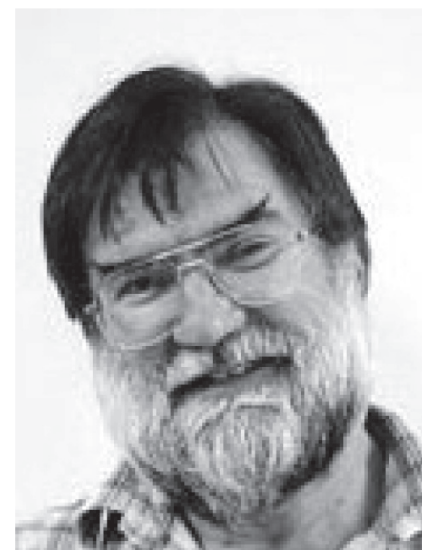

Tim Dunne

Department of Statistical Sciences, University of Cape Town Tim.dunne@uct.ac.za

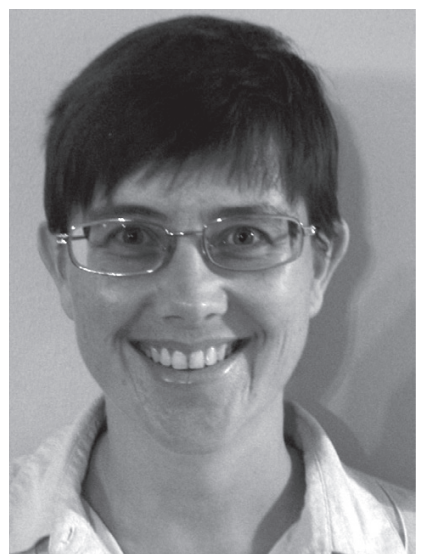

Tracy S. Craig ASPECT University of Cape Town Tracy.craig@uct.ac.za

\begin{abstract}
In the transition years, Grades 7 to 9 , the shift from natural numbers to rational numbers and the associated multiplicative concepts prove challenging for many learners. The new concepts, operations and notation must be mastered if the student is to thereafter rise to meet the challenges of algebra and more advanced and powerful mathematics. The multiplicative conceptual field (MCF) groups together such concepts as fraction, ratio, rate, percentage and proportion, all of which are related yet subtly distinct from one another, each with its own challenges. Rasch analysis allows us to compare the difficulty of mathematical problems located within the MCF while, on the same scale, locating the degree to which individual learners have mastered the necessary skill set. Such location of problems and learners on the same unidimensional scale allows for fine-grained analysis of which aspects of the problems being analysed make one problrm more difficult than another. Simultaneously the scale gives the teacher clear evidence of which students have mastered which concepts and skills and which have not, thereby allowing more targeted assistance to the class and individual learners. This paper illustrates the process involved in such analysis by reporting on results located within a larger study. It is suggested that implementing Rasch analysis within the school classroom on appropriately designed assessment instruments would provide clarity for the teacher on the locations of difficulty within the problems used in the assessment and the relative degree to which individual learners are achieving success at mastering the targeted concepts.
\end{abstract}

Keywords: Rasch measurement, multiplicative conceptual field, ratio and proportion, assessment 


\section{Introduction}

Usiskin (2005) asserts that the transition years, Grades 7 to 9 in the school mathematics curriculum, demand radical conceptual shifts, most notably from natural numbers to rational numbers and from rational numbers to real numbers. According to Skemp (1971) each new system retains elements of the previous system, but introduces new notation, new meanings to operations, and contributes additional rules.

In each new [number] system there are sub-sets which are isomorphic ${ }^{1}$ with earlier systems. This [isomorphism] allows us to move freely from one number system to another, and also to mix systems provided that each one is operated according to its own methods. The overall result is a conceptual system of enormous power and flexibility (Skemp, 1971, p. 226).

It is this structure of number systems that is the Rubicon for most learners of mathematics as they make the transition from whole numbers to rational numbers. Aspects of the system, for example, the fraction notation used for both fraction and ratio, are deceptively alike and yet subtly different. For learners of mathematics, assimilation into existing schema ${ }^{2}$ and modifying existing schema to incorporate new concepts are considerable challenges (Skemp, 1971). The new elements that have to be accommodated often comprise threshold concepts, the label used by Meyer \& Land (2005) to name concepts that involve a shift in perspective, thereby opening up a new conceptual space, which provides the necessary gateway to more complex and powerful concepts.

Additive structures, including the operations addition and subtraction ${ }^{3}$, are initially adequate for solving the problem situations young learners may encounter. The schemes used by young children when solving simple shopping or playground problems provide the basis for additive structures. As mathematics learning progresses, multiplicative structures are required for many problem situations, where formerly additive structures may have been sufficient. The situations of increasing complexity demand the development of multiplicative structures, including the operation of division by non-zero numbers, which together lead to more advanced concepts and procedures such as fractions, ratio and rate, percentages and functions.

The particular challenge encountered by the fields of education and psychology is to explicate how learners develop competences in mathematics and progressively master concepts of increasing complexity. A great deal of research has focused in detail on the analysis of mathematical concepts, the levels of difficulty and misconceptions likely to occur (Hart, 1984) and the complex interrelationship of concepts within a conceptual field (Sowder et al, 1998). Much research has also focused on the learners' thinking and reasoning in relation to a specific topic, for example fractions, percentage or proportional reasoning (Smith III, 2002; Parker \& Leinhardt, 1995; Misailidou \& Williams, 2003).

According to Piaget and Garcia (1989), the essential problem in education is "how to characterize the important stages in the evolution of a concept or a structure or even the general perspective concerning a particular discipline, irrespective of accelerations or regressions, the impact of precursors, or epistemological gaps" (p. 7). Vergnaud (1997) extends the description, from characterizing the evolution of a problem, to include the importance of tracking learner competences in relation to mathematical concepts. A feature of mathematics education research emphasized by Vergnaud $(1983 ; 1988)$ is that both the problem situations in which mathematical concepts are embedded and the cognitive skills required to solve the problems can most accurately be described using mathematical concepts and theorems. Other means of description, 
such as using language or levels of abstraction that are unrelated to mathematics, do not give the pertinent detail required, nor do they act as markers to indicate developmental progression.

The notion of "a general perspective" about mathematics that is foregrounded in this study is that the power of mathematics lies in the process of transforming the intuitive and implicit knowledge first used in the solving of problems or a class of problems, into explicit and generalisable knowledge that can be applied to more than one situation (Vergnaud, 1990). Research focused on a conceptual field accommodates the pervasive feature of mathematics that a problem situation can rarely be explained by a single concept, and a single concept cannot be explicated through only one mathematical context. The demarcation of the multiplicative conceptual field as the research terrain for this study locates this study within the theory of conceptual fields.

In this study the research problem is to locate the hierarchical development of mathematical concepts and the associated cognitive conceptions in problem situations invoking the multiplicative conceptual field, on a scale, which can then be used to describe and analyse difficulty levels and proficiency levels. Data on learner proficiency and item performance arises from a suitable test instrument. The Rasch model (Rasch, 1960/1980), a probabilistic model asserting that the probability of attaining a correct answer on an item is a function of the difference between difficulty level of the item and ability level of the student, was applied in this study. The application of the Rasch model to the data obtained from administering a suitable instrument leads to an interval qualitative scale against which item difficulty and current individual learner performance can be represented (Bond \& Fox, 2007). These Rasch measures on the tested construct enable the teacher to perceive, identify and address proximal zones of mathematical development ${ }^{4}$ in groups of learners.

It is imperative that research into aspects of mathematics teaching and learning be situated in a theory which encompasses an epistemology of mathematics, notions addressing how children acquire new concepts, the role of language and symbols, the role of the teacher and the function of assessment. The danger of not situating research in a comprehensive theory is that shortsighted decisions may be made as a result of research conceived against a set of criteria that does not match the envisaged educational outcomes.

\section{Theory of conceptual fields}

The theory of conceptual fields builds on the work of both Piaget and Vygotsky. The major contribution of Piaget (1949 as cited in Vergnaud, 1990) is that knowledge develops within a learner in response to dealing with his or her environment. In some cases new knowledge is assimilated into knowledge structures. In other cases the learner has to accommodate (i.e. alter) existing cognitive structures in order to engage with more complex learning. Different kinds of knowledge are developed from different kinds of abstraction, notably empirical abstraction, which is developed from isolating properties and relationships of external objects, and reflective abstraction which isolates properties and relationships of the person's own operations. Language is developed in response to action and is a factor in thinking, but actions for Piaget were more important than language. Vygotsky (1962) provides complementary views which stress the role of language and symbols in learning and thinking.

The theory of conceptual fields complements the socio constructivist work of Piaget in that it extends some of the concepts he developed to the teaching and learning environment. Secondly the development of mathematics concepts is investigated in terms of mathematics concepts and 
theorems, rather than reducing mathematics concepts to logic or levels of abstraction. Building on the work of Vygotsky, the roles of language and of symbols are incorporated into the theory of acquiring and developing mathematical concepts. The use of representation is extended to diagrams and tables, whose role is to articulate the relations between the elements of a problem, thereby providing the basis for symbolic thinking (Vergnaud, 1988). Elements from the intuitionist and formalist conception of mathematics education are also incorporated into this framework, where the concepts are appropriate to teaching and learning. In particular both the strength of intuitions in guiding or adapting schemes and the critical role of logic and formal structures for convincing a putative mathematical community (if only the classroom community) of the correctness of one's reasoning, are noted as essential.

Complementary to the mathematical concepts and theorems, are important psychological

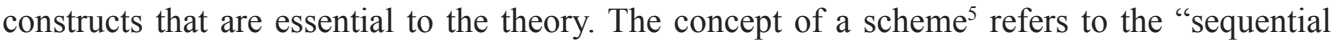
organization of activity for a (specific) situation" (Vergnaud, 2009, p. 84). For the purposes of this paper, a scheme is essentially a set of cognitive processes with which a learner engages in response to a problem situation. A critical factor is that a scheme embodies a goal to achieve. This aspect of a scheme may relate to other psychological factors deemed to be important for learning, such as motivation. The goal in mathematics learning may entail getting to the right answer, but it may also be to understand better the problem situation that is encountered; it may be to grasp a concept more fully, or it may be a combination of all these sub goals. A further characteristic of a scheme is that it embodies rules by which to generate actions (which may be procedures learned in class, or a learner's self-generated procedures, or a mixture of the two) and operational invariants (the enduring predispositions to identifying objects, finding patterns, recognizing concepts and applying procedures).

Two terms essential to the theory are concept-in-action and theorem-in-action. The first point to be made is that there is a dialectical relationship between concepts and theorems, in that there is no concept without a theorem and no theorem without a concept (Vergnaud, 2009). The concepts of addition and multiplication develop over a long period of time through situations that call for theorems at different levels. The terms concept and theorem are used to refer to specific mathematical objects; Vergnaud uses the terms concepts-in-action and theorems-in-action to describe the prototypes of concepts and theorems that develop as operational invariants in the schemes of the learner (Vergnaud, 1988). The importance of these concepts in this study is that the developing concepts and theorems can be recognized in the action procedures and language of the learner. This recognition enables the researcher or teacher to identify both the level of understanding and some potential formulation of a plausible next step along a particular learner's path to a more complete understanding of the concept being taught.

The task of describing a network of concepts that are related both hierarchically and horizontally required both theoretical investigation and empirical validation. One of the tasks of the larger study, and the focus of this paper, is to ascertain current learner competence levels, describe these levels and analyse the particular competences or lack of competences in terms of mathematics concepts and theorems.

The research questions addressed in this phase of the research for the larger study are;

1. What concepts-in-action and theorems-in-action are currently used by learners to solve the mathematical problem items located in the multiplicative conceptual field, in particular involving the elements fraction ratio, rate, proportion, probability and percent?

2. Upon which implicit concepts and theorems does each action procedure rely? 


\section{Research design and analysis procedures}

In the larger study from which this paper is drawn, a test was designed with 35 items selected from the Trends in International Mathematics and Science Study (TIMSS) Grade 8 released items, with 5 items from the Grade 4 set of released items (TIMSS, 2003), including both multiple choice and constructed response questions. The general validity of the test, including the items, was judged to be a valid representation of the construct, the multiplicative conceptual field, as conceptualised in this study. Messick (1989) requires additional validation of the use of the test scores and related inferences to be made in terms of the value implications, relevance and social consequences. When judged in terms of all these requirements, the test and the items meet the criteria.

The test was administered to all 330 Grades 7, 8 and 9 learners at two schools. The schools were selected on the grounds that they were well-functioning schools, whose learners were representative of the South African demographics. The purpose of this selection was to eliminate undue noise in the results that could be attributed to lack of instruction.

The application of the Rasch model resulted in the hierarchical location of item difficulty and learner proficiency as measured by this test, represented in the Person-Item map (see Figure 1). For purposes of analysis the item substrands that could be identified as constituting similar concepts were specified, for example a percent strand was identified. However it must be noted that the items invariably included more than one concept.

All 35 items were analysed in terms of the context of the problem, mathematical structure, concepts and processes, notation and representation, and number range (see Table 1). Interviews were conducted on four selected items at distinct graded difficulty levels and with from three to six selected learners ${ }^{6}$ drawn from each of the schools, at three graded levels of proficiency, as defined in terms of their location on the instrument scale. This selection was restricted to learners who were in Grade 8 at the time of taking the test.

The purpose of conducting learner interviews was firstly to provide additional insight into the performance of the items and distractors, and secondly to describe in general the competences of learners at particular scale location segments. In this paper the preliminary analysis of four items is shown. The results of four interviews, conducted on one of the four items and focused on the substrand, ratio, rate and proportion are discussed in this paper.

The learners, interviewed in groups of similar proficiency a few months after the test, were requested to answer four items from the original test, but on the second occasion to write down their calculations, even in the case of the multiple choice items. Once they had completed this task, they were asked to explain how they had reasoned about the problem. This explanation was recorded. As is to be expected, learners at the high proficiency levels had clearer and shorter explanations. For the learners exhibiting less mathematical proficiency and located at the low end of the scale, even the easiest of the interview items were a challenge.

The decision was made to engage with learners in the interviews in order to clarify their existing concepts-in-action and theorems-in-action and to establish the concepts with which the learner was able to engage. 


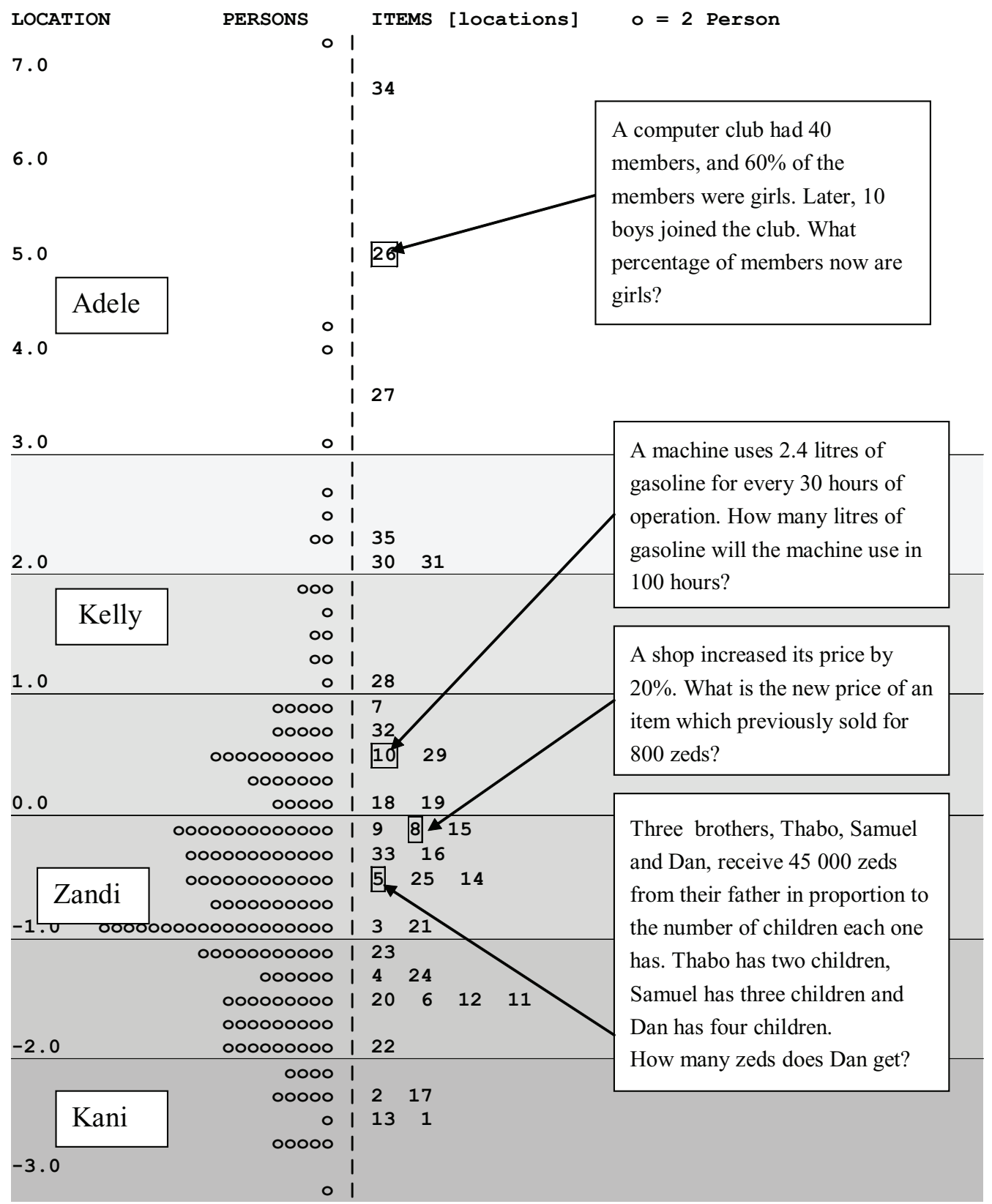

Figure 1: Person-Item map: location of learners and items

In the Rasch model, the locations of item difficulty level, and therefore complexity, and of learner proficiency being presented on the same scale enables partial identification of the hierarchical development of multiplicative constructs. The application of the model to an instrument requires that its construct of interest be theoretically defined and that the constituent items, the realizations of the construct, are hierarchically ordered in terms of difficulty ${ }^{7}$ level (see Figure 1). 
Likewise learners can be located on a scale in the sense that particular learners may be judged to have attained a level of proficiency on the unidimensional ${ }^{8}$ construct of interest. The location of items in terms of difficulty from greater levels to lesser levels, and the location of learners ranked in terms of greater observed proficiency to lesser proficiency are inserted on the same scale, through the process of transforming raw scores into logarithmic odds ratios (Rasch, 1960/1980; Andrich \& Marais, 2008).

\section{Item analysis}

The initial selection of items was in terms of the multiplicative structure that the item content exhibited. The items were required to cover a range of concepts including fractions, ratio, rate and proportion, percentage, probability, and there were items that elicited pre-algebraic ideas and methods. According to Vergnaud (1988, p. 143), the difficulty or complexity of an item depends on the context domain, the structure of the problem, the presentation and the numerical characteristics (number range and value) of the data. The analysis ${ }^{9}$ of four items based on these factors is shown in Table 2.

The Rasch Person-Item map shows items at graded levels of difficulty from greater at the top of the scale to lesser at the bottom of the scale. The mean of the item difficulties is arbitrarily set at zero. Likewise learner proficiencies are located along the scale from greater proficiency at the top of the scale to lower proficiency at the lower end of the scale. The five items, labelled 13, 1, 17, 2 and 22, which were found empirically to be the easiest items, were in fact the TIMSS Grade 4 items, selected in order to target the lower end of the range of learners being tested.

Supporting the Person-item map, but not presented in this paper, is a differential item fit (DIF) analysis. In Rasch model theory and analysis this DIF information amounts to a set of item-specific reliability measures, which permit the identification of items which give rise to anomalous features. Similarly it is also possible to identify specific learners whose patterns of correct and incorrect answers are not consistent with the empirical array of item difficulty levels associated with the full set of learners, but are anomalous, such as might arise from, say, random guessing. No evidence emerged to suggest any reliability problems from either prospective source. Conventional measures of reliability are not relevant here.

The learner locations are linked to the item locations in the following way: a person located at the same point on the scale as an item has a $50 \%$ chance of obtaining a correct answer on that item, a less than $50 \%$ chance of obtaining a correct answer for any item higher on the scale and a greater than $50 \%$ chance of obtaining a correct answer for any item that is lower on the scale. For example Item 5 (location - 0.585) is easier than most items. Learners at Zandi's location, just below Item 5 , have in theory slightly less than a $50 \%$ chance of obtaining a correct answer to this item. For learners located above the item on the scale, for example Adele and Kelly, the chance of obtaining a correct answer is substantially higher than $50 \%$.

The four items in Table 1, though drawn from the ratio and percent substrands, involve various contexts. It is to be expected that contexts with which learners may be familiar, for example, sharing money, may be easier for most learners than less familiar contexts, such as calculating percent increase. Of course a child helping his parent in a trading store may have gleaned some experience of percentage increase, and find this context more familiar than his peers may find it. 
In terms of the mathematical structure, all four items require multiple steps in the process of solving the problem. The first process required for Item 5 is to add the number of children (9); the second is to divide the total amount of money by the number of children to obtain an amount per child $(45000 / 9=5000)$; and the third is to multiply the number of Dan's children by the amount $(4 \mathrm{x} 5000)$. It is however expected that a child may not make the correct steps in the same sequence as outlined. Item 26 also requires three steps; the complexity, however lies in the change of referent from 40 to 50 midway through the problem-solving process. Locating the referent in percent calculations has been noted by Parker and Leinhardt (1995) as being particularly difficult.

Table 1: Four items at graded difficulty level used to interview learners

\begin{tabular}{|c|c|c|c|c|c|}
\hline Description & Context & $\begin{array}{c}\text { Mathematical } \\
\text { Structure }\end{array}$ & $\begin{array}{l}\text { Cognitive } \\
\text { processes } \\
\text { (concepts } \\
\text { and } \\
\text { theorems) }\end{array}$ & $\begin{array}{l}\text { Notation and } \\
\text { presentation }\end{array}$ & $\begin{array}{l}\text { Number } \\
\text { range and } \\
\text { value }\end{array}$ \\
\hline $\begin{array}{l}\text { 5. } 45000 \\
\text { zeds shared } \\
\text { in unequal } \\
\text { proportions }\end{array}$ & $\begin{array}{l}\text { Family } \\
\text { sharing } \\
\text { money }\end{array}$ & $\begin{array}{l}\frac{2}{9}: 3: 4 \\
\text { of } 45000 \\
=20000\end{array}$ & $\begin{array}{l}\text { Proportion, } \\
\text { fractions, } \\
\text { ratio, } \\
\text { multiplication }\end{array}$ & $\begin{array}{l}\text { Natural } \\
\text { language }\end{array}$ & $\begin{array}{l}\leq 45000 \\
\text { (thousands) }\end{array}$ \\
\hline $\begin{array}{l}\text { 8. Increase } \\
800 \text { zeds by } \\
20 \% .\end{array}$ & $\begin{array}{l}\text { Financial } \\
\text { context, } \\
\text { Price } \\
\text { increase }\end{array}$ & $\begin{array}{l}800+20 \% \text { of } \\
800 \\
100 \% \text { of } 800+ \\
20 \% \text { of } 800 \\
=120 \% \text { of } 800 \\
=960\end{array}$ & $\begin{array}{l}\text { Multiplication, } \\
\text { fractions, } \\
\text { percentage } \\
\text { increase }\end{array}$ & $\begin{array}{l}\text { Natural } \\
\text { language, } \\
\text { percent } \\
\text { notation }\end{array}$ & $\begin{array}{l}\leq 1000 \\
\text { (hundreds) } \\
\text { Percentages }\end{array}$ \\
\hline $\begin{array}{l}\text { 10. } 2.4 \text { litres } \\
\text { to } 30 \text { hours, } \\
\text { how much } \\
\text { for } 100 \\
\text { hours? }\end{array}$ & $\begin{array}{l}\text { Capacity- } \\
\text { time }\end{array}$ & $\begin{array}{l}2.4 \text { is to } 30 \\
\frac{x_{\text {is }} \text { to }}{30}=\frac{100 x}{100} \\
x=8.0\end{array}$ & $\begin{array}{l}\text { Decimal } \\
\text { fractions } \\
\text { Proportional } \\
\text { reasoning }\end{array}$ & $\begin{array}{l}\text { Natural } \\
\text { language, } \\
\text { decimal } \\
\text { notation }\end{array}$ & $\begin{array}{l}\leq 100 \\
\text { decimal } \\
\text { fractions }\end{array}$ \\
\hline $\begin{array}{l}26 . \text { Finding } \\
\text { number } \\
\text { given the } \\
\text { percentage. } \\
\text { Recalculating } \\
\text { percentage } \\
\text { with change } \\
\text { in whole } \\
\text { amount. }\end{array}$ & $\begin{array}{l}\text { Computer } \\
\text { club }\end{array}$ & $\begin{array}{l}60 \% \text { of } 40=24 \\
\begin{array}{c}\frac{40+10}{50}=\frac{10}{240 \times 2} \\
= \\
=40 \times 2\end{array}\end{array}$ & $\begin{array}{l}\text { Multiplication, } \\
\text { fractions, } \\
\text { percent, } \\
\text { Change of } \\
\text { referent }\end{array}$ & $\begin{array}{l}\text { Natural } \\
\text { language, } \\
\text { percent } \\
\text { notation }\end{array}$ & $\begin{array}{l}\leq 100 \\
\text { percentages }\end{array}$ \\
\hline
\end{tabular}

The notation and presentation, and the number range and value, also contribute to the difficulty level of items. In some cases a seemingly large number, for example, 45000 may not present great difficulty as it may be perceived as 45 thousands and therefore become easier to deal with, 
in the implicitly revised units. Diagrammatic and picture representations are easier than symbolic representations and may provide cognitive stepping stones towards more abstract understanding.

\section{Interview analysis}

In order to gain further insight into the complexity of the items, interviews were conducted with learners at varied levels of proficiency on four of the items. For the purposes of this paper the interviews on one of the items, Item 5, with four learners at graded levels of proficiency is discussed. Note that the learners were selected for the interviews on the basis of their contrasting locations on the scale that is Adele (location 4.13), Kelly (location 1.86), Zandi (location -0.82) and Kani (-2.71) (see Figure 1). Their responses to Item 5 are provided in Table 2.

Table 2: Learners' responses to Item 5

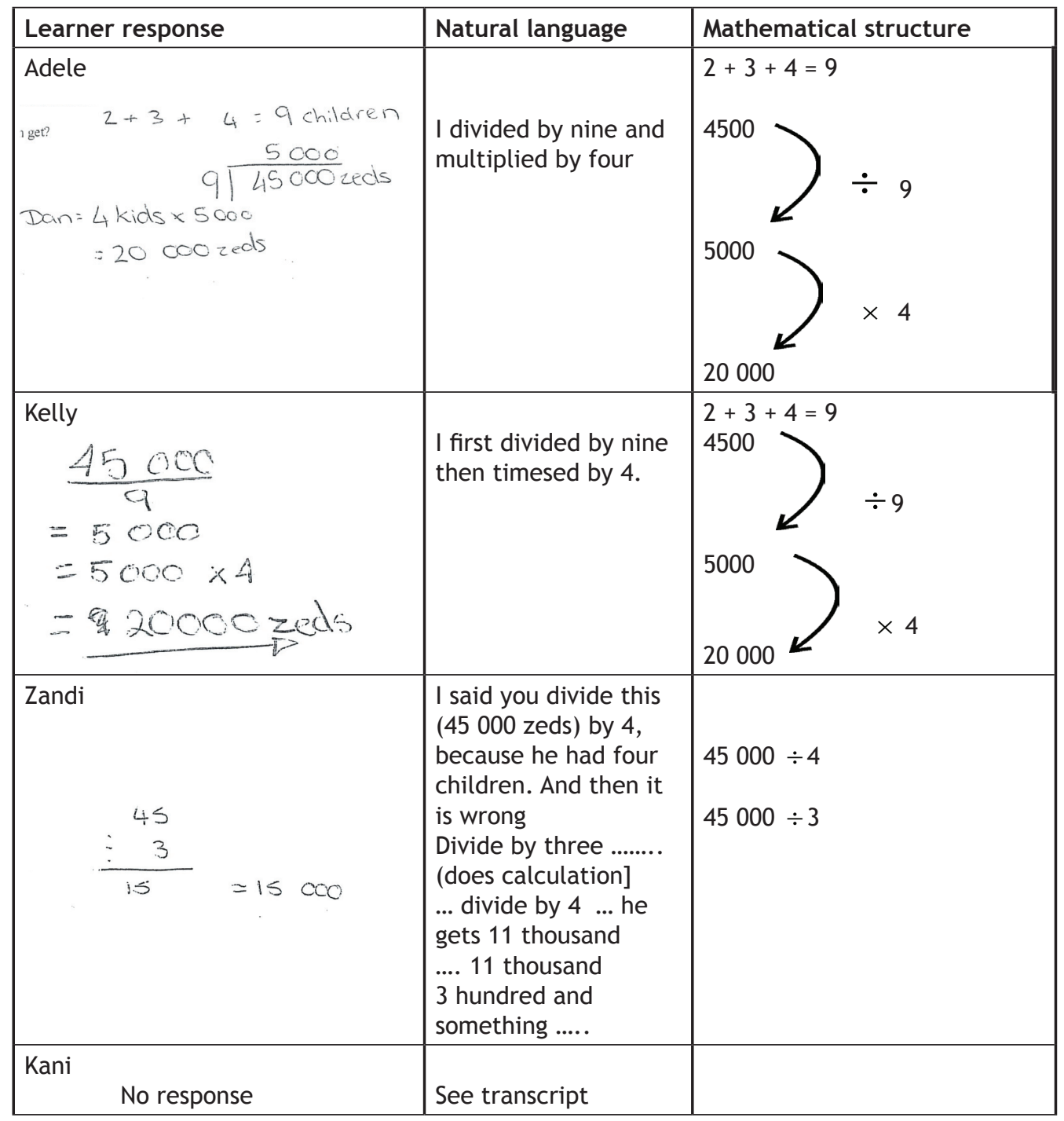


Learners Adele and Kelly both obtain a correct answer (see Table 2). However there are notable differences. The layout of Adele's calculation is accurate mathematically and her verbal explanation is clear. Kelly makes the mistake of using the equals sign as a separator between the mathematical statements rather than a symbol which denotes equality between the respective lines (Kieren, 1990). This misuse of the equal sign does not affect Kelly in this problem situation. It is part of a theorem-in-action and was noted in two of the other problem situations about which she was interviewed. The problem is that this error will become an obstacle for problems of greater complexity. By contrast the procedure used by Adele is generalisable to other problems of similar and more complex structure.

It appears that Zandi is not able to locate the mathematical relationships in the problem (see Table 2). Her scheme involves trial and error. The fact that the multiple choice distractors were available may have tempted her to guess at the procedure. She did however have a scheme with which to engage with the problem. Kani, on the other hand could not engage with the problem without probing and scaffolding on the part of the interviewer. He may have experienced reading problems, and in fact in the Item 10 interview transcript, Kani observes that a picture or a graph would be easier to understand (see Long, in process).

Kani did not attempt this problem situation. The interviewer engaged Kani in order to establish which concepts-in-action and theorems-in-action Kani used in order to attack the problem. It was essential to probe in order to establish what the stumbling blocks were. One of the problems not directly related to the mathematics was an inability to engage with the problem, either because of lack of focus or because of reading difficulties.

\begin{tabular}{|c|c|c|}
\hline Speaker & Transcript & $\begin{array}{l}\text { Mathematical structure and } \\
\text { language }\end{array}$ \\
\hline Interviewer & $\begin{array}{l}\text { Can you tell me how you thought about this } \\
\text { problem? }\end{array}$ & Concepts-in-action (addition, \\
\hline Kani & $\begin{array}{l}\text { The number of children counted altogether } \\
\text { is } 9 \text {, so I divide this } 45 \text { into the number of } \\
\text { children }\end{array}$ & $\begin{array}{l}\text { division); Theorem-in-action } \\
\text { (simple proportion) }\end{array}$ \\
\hline Interviewer & $\begin{array}{l}\text { So you divided ... the number of children is } \\
\text { nine ... and the amount of money? }\end{array}$ & \\
\hline Kani & $\begin{array}{l}45 \text {, so } 45 \text { divided by nine ... the answer is } \\
\text { five. }\end{array}$ & $\begin{array}{l}\text { Multiplicative structures not } \\
\text { stable }\end{array}$ \\
\hline Interviewer & $\begin{array}{l}\text { So just read through the question again } \\
\text { (after about } 2 \text { minutes) }\end{array}$ & $\begin{array}{l}\text { Problems understanding the } \\
\text { text }\end{array}$ \\
\hline Kani & Ohhhh ... now I get it ... okay I get it ... & \\
\hline Interviewer & So what is the answer? & \\
\hline Kani & $\begin{array}{l}\text { Oh miss, let me see ..... (reads through) } \\
\text { (after about } 30 \text { seconds) }\end{array}$ & \\
\hline Interviewer & How many children does Dan have? & \\
\hline Kani & He has four children & \\
\hline Interviewer & $\begin{array}{l}\text { So you say Dan has four children. What does } \\
\text { the } 5000 \text { zeds represent? }\end{array}$ & \\
\hline Kani & The one child & \\
\hline Interviewer & And so for four children ...? & \\
\hline Kani & The four children altogether make $20 \ldots$ & Uses 20 rather than 20000 \\
\hline Interviewer & So which is the correct answer? & \\
\hline Kani & Oh, for Dan it is 20. Okay, now I get it. & \\
\hline
\end{tabular}


In spite of the difficulties, Kani was able to understand the problem and with scaffolding was able to recognize and therefore act on some of the prompts provided by the interviewer. It appears that items exhibiting this mathematical structure and these concepts are within Kani's zone of proximal development (Vygotsky, 1962). However it can also be argued that greater fluency with language may assist access to greater mathematical proficiency through these transition years.

\section{Discussion}

This paper provides a short excerpt from the larger study investigating proficiency in the multiplicative conceptual field. The Rasch model provides a theoretical and methodological tool for the research design, and the data analysis. In this excerpt the preliminary analysis of four of the thirty-five items has been provided. In addition an in-depth discussion has been presented of only one of the four items on which interviews were conducted with only one of the 24 learners. The claims made on this snapshot of the larger study are necessarily provisional; the potential of the methodology to provide levels of competence, as a result of the analysis of the 35 items and selected interviews is foregrounded in this paper.

The Rasch method made it possible to choose interviewees and problems carefully targeted to reveal a range of concepts-in-action and theorems-in-action. While Adele revealed a mature theorem-in-action of proportional reasoning, Kelly demonstrated the same technique but with a less sophisticated conceptual understanding of the role of the equal sign. Zandi demonstrates that her developing concepts-in-action of ratio and proportion require additional support before reaching the desired level. The interview with Kani confirms that his understanding of ratio and proportion is the weakest of the four, as the Rasch Person-Item map indicates, but that the solution of the problem is within his zone of proximal development and is hence within his grasp if sufficient support is provided by the teacher or peers.

The theory of conceptual fields provides a framework that includes complementary foundational mathematical elements from different perspectives. Socioconstructivism is acknowledged as contributing to an understanding of how children acquire mathematical concepts but other perspectives, namely intuitionism and formalism, are acknowledged for the contributions that they make to the development of mathematical constructs. Mathematics, its concepts and theorems are the essence of the theory of conceptual fields. In addition, the theory, being underpinned by the work of Piaget and Vygotsky, includes the psychological constructs necessary to understand cognitive structures. The theory also provides the tools for analysis of problem situations and learner responses. Vergnaud (1988) stresses the importance of analyzing both mathematical situations and learner schemes, in terms of mathematical constructs, so that the path of mathematical development may be identified and therefore guide instruction.

The requirements of the Rasch measurement model resonate with the theory of conceptual fields in that both item difficulty and learner proficiency are located on the same scale. The selection of items at graded difficulty levels and learners at various proficiency levels allows a complementary analysis which serves both the purpose of research and the purpose of teaching to foster the mathematical development of learners. The locations (see Figure 1) of Adele (4.13), Kelly (1.86), Zandi (0.82), and Kani (-2.71) each represent four distinct sets of learners at the same levels of proficiency. The analysis of items, exhibiting concepts and procedures that are located at the difficulty level of the learners and the analysis of the schemes employed by learners in solving these problems may, with additional support, inform teaching. 
The strength of locating the research problem in a theory which encompasses an epistemology of mathematics and notions concerning essential elements of the education process guarantees that there is the potential for coherence of theoretical concepts, research design, data analysis and recommendations about envisaged educational processes and responses.

\section{Notes}

1. Two number systems are isomorphic if 1 ) there is a mapping of one into the other that puts them into one-to-one correspondence, and 2) under this mapping, sums and products are preserved.

2. Schema is the term used by Skemp (1971) to refer to conceptual structures. The term scheme is used in this study, and is defined as "the invariant organisation of behaviour for a [particular] class of situations" (Vergnaud, 1998, p.167). The term "invariant organization" is interpreted in this paper to mean an enduring rather than unalterable predisposition to seek, mimic, or impose contrasts, similarities, patterns and relationships on one's environment.

3. Following Sfard (1995), mathematical objects are considered to comprise both structural and operational properties as "two sides of the same coin". In early mathematical development, addition and subtraction are both regarded as operations.

4. Proximal zones of mathematical development refer to area between the current level of proficiency and the potential level of proficiency that is reached through instruction.

5. According to Vergnaud (2009), the term scheme was introduced by Kant and used by various French philosophers in the early $20^{\text {th }}$ century: Piaget provided concrete examples of its significance.

6. Six learners were identified at each of three locations at each of the two schools. These names were supplied to the teacher concerned who requested parental approval for participation on our behalf. Some of the children were not available.

7. The term difficulty in this sense is used to mean "require more ability".

8. The notion of unidimensionality receives finer analysis in Andrich (2006). A test construct may contain greater or lesser 'bandwidth', a feature which does not contradict unidimensionality.

9. Further analysis in terms of the selection of distractors and inferences about the selection of distractors was conducted for all items. This further analysis is not shown here.

\section{References}

Andrich, D. (2006). On the fractal dimension of social measurement. Unpublished paper, Social Measurement Laboratory, Murdoch University, Perth, Australia.

Andrich, D., \& Marais, I. (2008). Introductory course in Rasch measurement. Perth: University of Western Australia.

Bond, T. \& Fox, C. (2007). Applying the Rasch Model: fundamental measurement in the human sciences. New Jersey: Lawrence Erlbaum Associates.

Hart, K. (1984). Ratio: Childrens 'Strategies and Errors. Windsor: NFER-NELSON.

Kieren, C. (1990). Cognitive processes involved in learning School Algebra. In P. Nesher \& J. Kilpatrick (Eds.), Mathematics and Cognition: A Research Synthesis by the International Group for the Psychology of Mathematics Education, (pp. 96-112). Cambridge: Cambridge University Press.

Long, C. (in process). The mathematical, cognitive, semiotic and instructional foundations of elements within the multiplicative conceptual field: Application of the Rasch model in the multidimensional analysis. 
Messick, S. (1989). Meaning and Values in test validation: The science and ethics of assessment. Educational Researcher, 18(2), 5-11.

Meyer, J. H. F., \& Land, R. (2005). Threshold concepts and troublesome knowledge (2): Epistemological considerations and a conceptual framework for teaching and learning. Higher Education, 49, 373-388.

Misailidou, C., \& Williams, J. (2003). Diagnostic assessment of children's proportional reasoning. Journal of Mathematical Behavior, 22, 335-368.

Parker, M. \& Leinhardt, G. (1995). Percent: A privileged proportion. Review of Educational Research, 65(4), 421-481.

Piaget, J. \& Garcia, R. (1989). Psychogenesis and the history of science. New York: Columbia University Press.

Rasch, G. (1960/1980). Probabilistic models for some intelligence and attainment tests. (Copenhagen, Danish Institute for Educational Research). Expanded edition (1980) with foreword and afterward by B. D. Wright, (1980) Chicago: The University of Chicago Press.

Sfard, A. (1995).The development of Algebra: Confronting historical and psychological perspectives. Journal of Mathematical Behaviour, 14, 15-39.

Skemp, R. (1971). The psychology of learning mathematics. Harmondsworth: Penguin.

Smith III, J. P. (2002). The development of students' knowledge of fractions and ratios. In B. Litwiller (Ed.), Making sense of fractions, ratio and proportion, 3-17. Reston, Virginia: The National Council of Teachers of Mathematics.

Sowder, J. T, Philipp, R. A., Armstrong, B. E., and Schappelle, B. P. (1998) Middle-Grade teachers' mathematical knowledge and its relationship to instruction. Albany: State University of New York.

Trends in International Mathematics and Science Study (TIMMS). (2003). Mathematics released items. Retrieved from: URL http://timss.bc.edu/timss2003i/released.html on 30 September 2006.

Usiskin, Z.(2005). The importance of the transition years, Grades 7-10, in school mathematics. UCSMP Newsletter. Spring 2005, 4-10.

Vergnaud, G. (1983). Multiplicative structures. In R. Lesh and M. Landau (Eds.), Acquisition of mathematics concepts and processes. (pp. 127-174). New York: Academic Press.

Vergnaud, G. (1988). Multiplicative structures. In J. Hiebert \& M. Behr (Eds.), Number concepts and operations in the middle grades (pp141-161). Hillsdale, NJ: National Council of Teachers of Mathematics.

Vergnaud, G. (1990). Epistemology and psychology of mathematics education. In P. Nesher \& J. Kilpatrick (Eds.), Mathematics and cognition: A research synthesis by the International Group for the Psychology of Mathematics Education. Cambridge: Cambridge University Press.

Vergnaud, G. (1997). The nature of mathematical concepts. In T. Nunes \& P. Bryant (Eds.), Learning and teaching mathematics: An international perspective (pp. 5-28). Hove: Psychology Press.

Vergnaud, G. (1998). A comprehensive theory of representation for mathematics education. Journal of Mathematical Behaviour, 17(2), 167-181.

Vergnaud, G. (2009). The theory of conceptual fields. Human Development, 52, 83-94

Vygotsky, L. (1962). Thought and language. Cambridge: MIT Press. 